\title{
Upaya Meningkatkan Pemahaman Bermain Bolavoli melalui Model Role Playing
}

\author{
Dini Noerfalah, Lukmannul Haqim Lubay, Didin Budiman
}

Universitas Pendidikan Indonesia, Indonesia

Info Artikel
SejarahArtikel:
Diterima Agustus 2019
Disetujui September 2019
Dipublikasikan Oktober 2019

Keywords:
Bola voli, Role playing

\begin{abstract}
Abstrak
Penelitian ini bertujuan untuk mengetahui apakah penerapan model role playing dapat meningkatkan pemahaman bermain siswa dalam bermain bolavoli. Penelitian ini menggunakan penelitian tindakan kelas. Penelitian dilakukan dalam dua siklus, setiap siklus dilaksanakan sebanyak dua kali tindakan penelitian. Subjek penelitian adalah kelas $\mathrm{V}$ disalah satu sekolah dasar di Kota Bandung sebanyak 30 siswa (laki-laki: 12; perempuan: 18). Model role playing dikombinasikan dengan instrument Game Performance Analisis Instrumen. Data dianalisis menggunakan teknik persentase dan dikaitkan dengan keterampilan bermain. Hasil penelitian menunjukan model pembelajaran role playing dapat meningkatkan pemahaman bermain bolavoli.
\end{abstract}

\begin{abstract}
The purpose of this research is to investigate how role playing method can improve student understanding in volleyball games activities. This research use class action research. The research used in two cycle, every cycle have research action that done twice. The subject of this research is 30 students of level 5 class from one elementary school in Bandung. (12 boys, 18 girls). Role playing models combine with GPAI instrument. Data is analyzed using percentage technic and associated with games performance. This research showed that role playing models can improve student understanding in volleyball games.
\end{abstract}




\section{PENDAHULUAN}

Di Pendidikan adalah usaha sadar yang merancang pembentukan perilaku dan tumbuh kembang manusia. Pendidikan adalah usaha sadar dan terencana untuk mewujudkan suasana belajar dan proses pembelajaran agar peserta didik secara aktif mengembangkan potensi dirinya untuk memiliki kekuatan spiritual keagamaan, pengendalian diri, kepribadian, kecerdasan, akhlak mulia, serta keterampilan yang diperlukan dirinya, masyarakat dan negara (UU No. 20,2003). Pendidikan itu sangat penting untuk keseluruhan umat manusia. Untuk mewujudkan itu semua, memerlukan generasi-generasi yang pintar, bertanggungjawab dan memiliki jiwa raga yang sehat, salah satunya dengan pendidikan jasmani. Pendidikan jasmani merupakan salah satu usaha sadar untuk menciptakan lingkungan yang mampu mempengaruhi potensi peserta didik agar berkembang ke arah tingkah laku yang positif melalui aktivitas jasmani (Utama, 2011).

Kontribusi unik pendidikan jasmani terhadap pendidikan secara umum adalah perkembangan tubuh yang menyeluruh melalui aktivitas jasmani. Jika aktivitas jasmani ini dipandu oleh para guru yang kompeten, maka hasil berupa perkembangan utuh insani menyertai perkembangan fisikal-nya Rink (Abduljabar, 2011). Hal ini dapat dicapai ketika aktivitas jasmani menjadi budaya dan kebiasaan jasmani atau pelatihan jasmani.

Berdasarkan beberapa uraian diatas dapat disimpulkan bahwa pendidikan jasmani adalah proses pendidikan yang menggunakan aktivitas jasmani melalui aktivitas fisik, permainan dan cabang olahraga sebagai wahana untuk meningkatkan kemampuan siswa agar berkembang secara menyeluruh baik, fisik, mental, kogintif maupun sikap kepribadiannya.

Dalam hal ini guru pendidikan jasmani di- harapkan bisa melaksanakan prosesnya sesuai dengan karakteristik siswa sekolah dasar. Dalam hal ini perlu adanya pembaharuan dalam merancang pembelajaran pendidikan jasmani yang sesuai dengan tujuan dan tingkat perkembangan siswa, akan tetapi pada kenyataannya dalam pembelajaran pendidikan jasmani masih jauh dari yang diharapkan, karena untuk mencapai proses pembelajaran yang efektif banyak faktor yang menjadi penghambat dalam proses pelaksanaannya. Sejalan dengan hal yang terjadi di SD Pertiwi Kec. Bandung Wetan yang menjadi tempat observasi penulis dalam proses pembelajaran masih sangat kurang baik dalam melaksanakan tugas gerak yang diajarkan oleh guru, salah satunya dalam pembelajaran permainan bola voli.

Permasalahan yang terjadi pada saat proses pembelajaran permainan bola voli di kelas V SD Pertiwi Kec. Bandung Wetan sangat tidak efektif karena rendahnya kemampuan siswa, serta kemampuan pada pemahaman siswa tentang permainan bola voli menyebabkan antusias siswa dalam kegiatan pembelajaran permainan bola voli terlihat sangat kurang efektif, misalnya: siswa menjadi lebih cepat bosan pada pembelajaran permainan bola voli serta terlihat bingung dengan peraturan permainan bola voli.

Dari permasalahan yang terjadi pada pembelajaran permainan bola voli kebanyakan dari pihak perempuan yang mengeluh untuk tidak mau melakukan permainan bola voli. Banyak siswa yang tidak nyaman dalam melakukan permainan bola voli dikarenakan siswa bingung dengan peraturan dan kurang menguasai keterampilan teknik dasar delam permainan bola voli. Dalam proses pembelajaran pendidikan jasmani di tingkatan sekolah dasar, pemahaman pembelajaran bola voli harus dijelaskan secara menarik, karena tidak semua siswa menyukai 
permainan bola voli dengan berbagai alasan. Tentunya guru pendidikan jasmani harus mampu membuat suasana pembelajaran yang menarik sehingga peserta didik termotivasi untuk belajar menikmati jenis permainan itu (permainan bola voli dan sejenisnya). Peserta didik sangat mungkin untuk diberi pemahaman tentang permainan bola voli agar siswa merasa senang saat melakukan pembelajaran permainan bola voli dengan menerapkan model role playing.

Role Play adalah suatu model pembelajaran yang bertujuan untuk membantu siswa menemukan makna diri (jati diri) di dunia sosial, mempelajari nilai-nilai sosial dan moral serta pencerminannya dalam perilaku memecahkan dilema dengan bantuan kelompok (Astuti, E. D., \& Sutarni, S., 2016). Berarti role play atau bermain peran merupakan pembelajaran yang berfungsi untuk menumbuhkan imajinasi siswa, keaktifan siswa dan argumen-argumen siswa untuk memecahkan permasalahan yang ada. Dengan menggunakan model role play, siswa bisa bermain peran berdasarkan kemampuan mereka. Melatih percaya diri mereka, kemudian ketika mereka sudah mulai percaya diri otomatis mereka tidak takut lagi untuk melakukan yang di intruksikan oleh guru. Seperti yang peneliti ambil ini menggunakan permainan bola voli dengan model role playing. Jadi para siswa bisa menemukan apa yang harus mereka lakukan ketika bermain bola voli. Contohnya mengambil keputusan ketika hendak memberikan passing bawah kepada teman sejawatnya. Kemudian mengambil keputusan ketika mereka melakukan passing atas dan memberikannya kepada teman se-timnya agar bisa mematikan permainan lawan dan mendapatkan point untuk timnya.

Model role playing ini lebih mengutamakan ketangkasan mereka dalam menampilkan jati diri mereka. Dilihat dari cara mereka mengambil keputusan, mendukung teman se-timnya, dan mencari ruang kosong ketika permainan berlangsung. Peneliti disini menggunakan model role playing dikarenakan menurut peneliti model ini cocok digunakan dalam permainan bola voli. Permainan bola voli di tuntut untuk banyak berpikir terutama dalam pengambilan keputusan (decision making) dan keterampilan bermain (skill execution). Maka dari itu diperlukan jati diri yang baik agar bisa cepat mengambil keputusan. Menggunakan model role playing ini bisa memberikan gambaran kepada peneliti untuk lebih memberikan keleluasan kepada siswa dalam mengeksplorasi diri. Agar para siswa bisa menjadi individu yang lebih berkembang tidak menjadi pemalu bahkan tidak mau ikut dalam pembelajaran penjas terutama dalam permainan bola voli.

\section{METODE}

enis penelitian yang peneliti gunakan dalam penelitian ini adalah penelitian tindakan kelas (classroom action research) yang mengacu pada model penelitian tindakan dari Kemmis \& MC Taggart (dalam Arikunto, 2013, hlm. 137). Adapun model PTK yang dimaksud menggambarkan adanya empat langkah (dan pengulangannya). Penelitian ini dilakukan dengan 2 siklus dan setiap siklusnya terdiri dari 2 tindakan. Sehingga semuaya berjumlah 4 pertemuan, satu tindakan merupakan satu pertemuan.Dalam penelitian ini yang menjadi populasinya adalah siswa kelas $\mathrm{V}$ di salah satu sekolah dasar di Kota Bandung, yang terdri dari 30 siswa, 12 siswa laki-laki dan 18 siswa perempuan.

Instrumen dalam penelitian ini menggunakan lembar observasi, catatan lapangan, dan rekaman foto. Lembar observasi menggunakan format observasi aspek kognitif, afektif (perilaku tanggung jawab Hellison dalam buku Suherman (2009, hlm. 90), dan aspek psiko- 
motor (keterampilan double dutch dari Australian Rope Skipping Association). Setelah data terkumpul, data tersebut kemudian diolah dengan mencari nilai rata-rata (), lalu mencari simpangan ba$\mathrm{ku}(\mathrm{s})$, setelah itu menghitung persentasenya, terakhir dihitung melalui penilaian acuan norma (PAN).

\section{HASIL DAN PEMBAHASAN}

Penelitian dilakukan untuk mengetahui bagaimana hasil dari setiap tindakan yang dilakukan apakah keterampilan bermain bolavoli meningkat atau tidak. Dari hasil observasi awal yang telah diteliti oleh peneliti tersaji di dalam gambar 1.

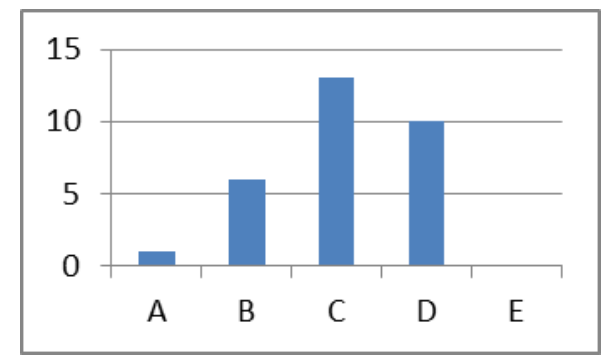

Gambar 1. Hasil Observasi Awal Aspek Kognitif

Berdasarkan hasil observasi awal pada gambar 1, peneliti menemukan bahwa pengetahuan siswa mengenai bolavoli masih sangat rendah, siswa yang mendapatkan nilai $\mathrm{A}=1(3,33 \%), \mathrm{B}=6$ (20,00\%), C=13 (43,33\%), D=10 (33,33\%), dan $\mathrm{E}=0(0 \%)$. Nilai rata-rata dari seluruh siswa adalah $43,03 \%$,

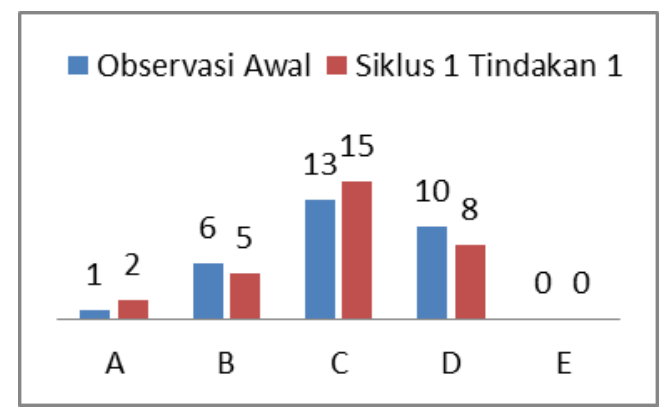

Gambar 2. Hasil Siklus 1 Tindakan 1
Berdasarkan hasil siklus 1 tindakan 1 pada gambar 2, peneliti menemukan bahwa pengetahuan siswa mengenai permainan bolavoli masih rendah, siswa yang mendapatkan nilai $A=2$ (6,67\%), B=5 (16,67\%), $C=15 \quad(50,00 \%), D=8$ $(26,67 \%)$, dan $\mathrm{E}=0(0 \%)$. Nilai rata-rata dari seluruh siswa adalah $53,00 \%$,

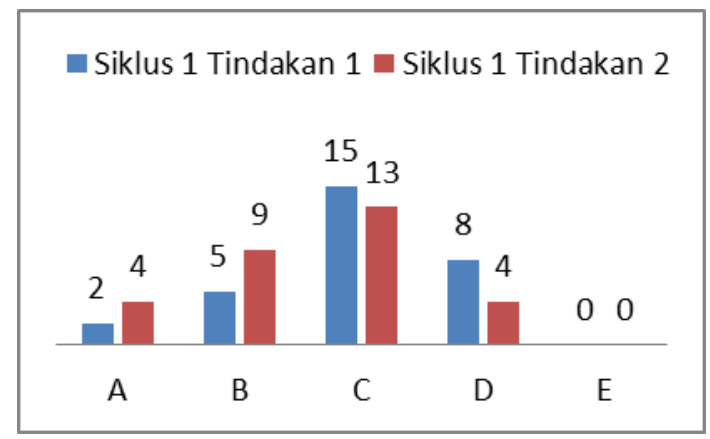

Gambar 3. Hasil Siklus 1 Tindakan 2

Berdasarkan hasil siklus 1 tindakan 1 pada gambar 3, peneliti menemukan bahwa pengetahuan siswa mengenai permainan bolavoli meningkat, siswa yang mendapatkan nilai $\mathrm{A}=4$ (13,33\%), B=9 (30,00\%), C=13 (43,33\%), D=4 $(13,33 \%)$, dan $E=0(0 \%)$. Nilai rata-rata dari seluruh siswa adalah $69,00 \%$.

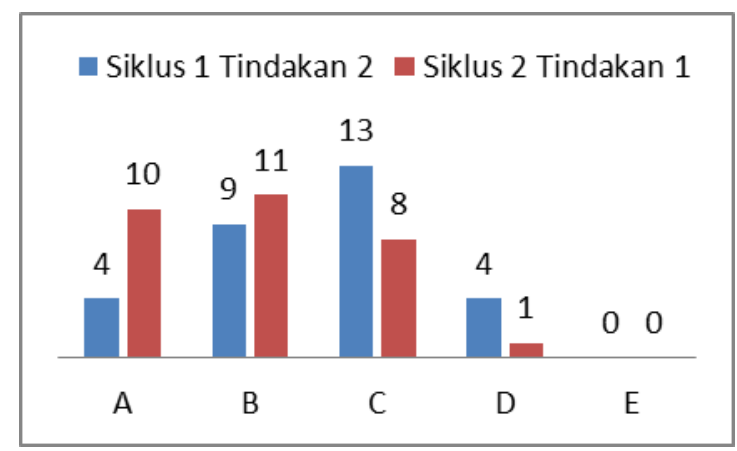

Gambar 4. Hasil Siklus 2 Tindakan 1

Berdasarkan hasil siklus 1 tindakan 1 pada gambar 7, peneliti menemukan bahwa pengetahuan siswa mengenai permainan bolavoli meningkat, siswa yang mendapatkan nilai $\mathrm{A}=10$ (33,33\%), B=11 (36,67\%), C=9 (26,67\%), D=1 
$(3,00 \%)$, dan $\mathrm{E}=0$ (0\%). Nilai rata-rata dari seluruh siswa adalah $80 \%$.

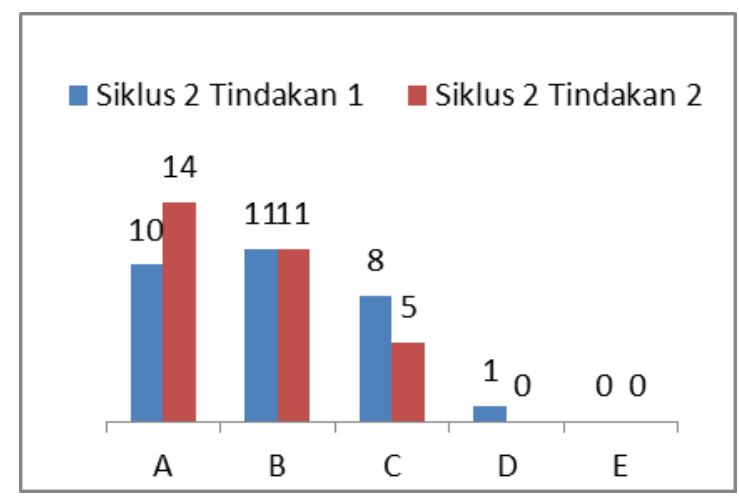

Gambar 5. Hasil Siklus 2 Tindakan 2 Aspek kognitif

Berdasarkan hasil siklus 2 tindakan 2 pada gambar 5 peneliti menemukan bahwa pengetahuan siswa mengenai permainan bolavoli meningkat, siswa yang mendapatkan nilai $\mathrm{A}=14$ (46,67\%), B=11 (36,67\%), C=5 (16,67\%), D=0 $(0 \%)$, dan $\mathrm{E}=0$ (0\%). Nilai rata-rata dari seluruh siswa adalah $85 \%$.

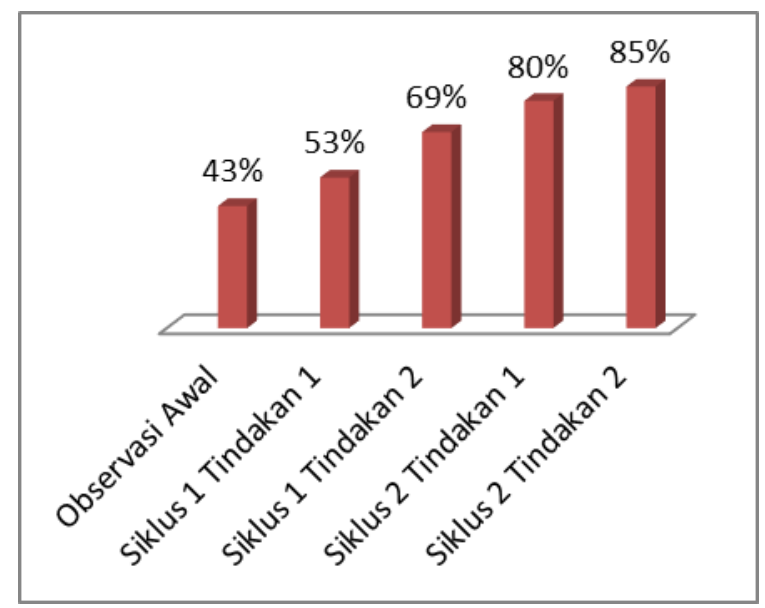

Gambar 6. Hasil Akhir

Berdasarkan hasil akhir penelitian pada gambar 6, peneliti menemukan bahwa pengetahuan siswa dalam pembelajaran bermain bolavoli mengalami peningkatan persentase setiap siklus dan tindakannya, pada observasi awal, per- sentase keseluruhan siswa sebesar $(43,03 \%$,$) , pada$ siklus 1 tindakan 1 persentase keseluruhan siswa (53,00\%), lalu pada siklus 1 tindakan 2 persentase keseluruhan siswa $(69,00 \%$.), kemudian siklus 2 tindakan 1 persentase keseluruhan siswa (69,00\%), dan pada akhir siklus 2 tindakan 2 persentase keseluruhan siswa (85,63\%). Dengan demikian, proses pembelajaran bermain bolavoli melalui model role playing yang diberikan dapat tercapai sesuai dengan tujuan pembelajaran yang diharapkan.

Setelah penulis bertindak sebagai peneliti dan guru (yang terjun langsung melakukan kegiatan mengajar) serta dibantu peneliti (sebagai observer) dalam melakukan penelitian tindakan kelas dari awal sampai tahap akhir penelitian. Dari hasil observasi awal diperoleh fakta bahwa guru tidak memberikan materi tentang mengoper bola, menguasai bola dan menjatuhkan bola ke ruang kosong lawan yang berupa dari pemanasan melalui permainan yang mengandung dari ketiga keterampilan yaitu mengoper bola, menguasai bola dan menjatuhkan bola ke ruang kosong lawan. Guru dalam memeberikan pembelajaran kepada siswa tidak tersusun secara sitematik sehingga banyak siswa yang tidak mau mengikuti dengan alasan tugas gerak dalam pembelajaran permainan bolavoli yang akan di pelajari terlalu susah.

Sedangkan dari hasil pelaksanaan tindakan kelas diperoleh penyajian pembelajaran melalui model role playing dalam pembelajaran permainan bolavoli dapat meningkatkan keterampilan bermain siswa dalam mengoper bola, menguasai bola dan menjatuhkan bola ke ruang kosong lawan. Role playing merupakan salah satu cara guru untuk mengatasi kesulitan siswa dalam pembelajaran, karena pada hakikatnya pendidikan jasmani memperhatikan perbedaan fisik dan 
psikis peserta didik.) Karena pada hakekatnya aktivitas pembelajaran dengan konsep penjas sangat memperhatikan adanya perbedaan dalam kemampuan fisik, psikis, maupun sosial, dan emosional peserta didik, sehingga dalam implementasi pembelajaran apapun di lapangan, harus mempertimbangkan adanyanya perbedan - perbedaan tersebut, oleh karena itu gurupenjas seringkali harus membuat berbagai aktivitas permainan itu berbeda untuk setiap kelompok peserta kegiatan (Bahagia, 2010. Pemberian dan penyajian tantangan melaksanakan tugas gerak sebaiknya harus berupa permainan agar anak merasa senang dan antusias dalam pembelajaran. Bermain merupakan kegiatan yang mereka lakukan sepanjang hari karena bagi anak bermain adalah hidup dan hidup adalah permainan (Suartini, K., Jampel, I. N., \& Antara, P. A.,2016). Dengan demikian jika anak melakukan permainan, maka anak akan menikmati pembelajaran yang di berikan oleh gurunya. Dan materi yang disampaikan oleh guru tersampaikan secara menyeluruh, namun dalam unsur bentuk-bentuk permainan yang menarik.

\section{KESIMPULAN}

Berdasarkan hasil penelitian dari mulai observasi awal sampai dengan siklus kedua tindakan satu, dapat diketahui bahwa pemahaman bermain bolavoli dapat ditingkatkan melalui model role playing. Peningkatan tersebut terlihat pada keterampilan mengoper bola, menguasai bola, dan menjatuhkan bola ke ruang kosong lawan. Keberhasilan proses pembelajaran karena menggunakan pembelajaran permainan role playing yang membuat siswa mau untuk melakukan aktivitas gerak sehingga dapat mengembangkan pemahaman bermain siswa dalam kegiatan pembelajaran permainan bolavoli.

\section{DAFTAR PUSTAKA}

Althoff, T., White, R. W., \& Horvitz, E. (2016). Influence of Pok_emon go on physical activity: Study and implications. Journal of Medical Internet Research, 18(12), e315. https:// doi.org/10.2196/jmir.6759.

Abduljabar B. (2011). Pedagogi Olahraga. POR FPOK UPI. Bandung. Red Point

Arikunto, Suharsimi. "Metode Penelitian Kuantitatif Kualitatif dan R\&D." Alfabeta: Bandung (2013).

Astuti, E. D., \& Sutarni, S. (2016). Pengaruh Pembelajaran Role Play dan Guided Discovery terhadap Hasil Belajar Matematika Ditinjau dari Aktivitas Belajar Siswa.

Bahagia. (2010). Media Pembelajaran Penjas. Bandung : FPOK UPI

Primasari, Rustiana (2011) dalam Endah DP Astuti, Sri Sutarni

Suartini, K., Jampel, I. N., \& Antara, P. A. (2016). PENERAPAN METODE BERMAIN FLASHCARD UNTUK MENINGKATKAN KEMAMPUAN BERBICARA BAHASA INDONESIA ANAK KELOMPOK A SEMESTER II DI TK NEGERI DESA TIGAWASABULELENG TAHUN PELAJARAN 2015/2016. Jurnal Pendidikan Anak Usia Dini Undiksha, 4(2).

Undang-Undang Sisdiknas. (2003) . hlm. 1. Diakses di: http://pendis.kemenag.go.id/pai/file/ dokumen/SisdiknasUUNo.20Tahun2003.pdf

Utama, A.M.B. (2011). Pembentukan karakter anak melalui aktivitas bermain dalam pendidikan jasmani. Jurnal pendidikan jasmani indonesia, 8 (1), hlm. 1-9 